\title{
Eighth Grade Students Conceptions of How Engineers Use Math and Science in the Field of Engineering: A Comparison of Two Cohorts
}

\author{
Donna Farland-Smith ${ }^{1}$, Vinta Tiarani ${ }^{1}$ \\ ${ }^{1}$ The Ohio State University, USA \\ Correspondence: Donna Farland-Smith, The Ohio State University, USA. \\ Received: June 30, $2016 \quad$ Accepted: July 19, $2016 \quad$ Online Published: September 5, 2016 \\ doi:10.11114/jets.v4i10.1861 URL: http://dx.doi.org/10.11114/jets.v4i10.1861
}

\begin{abstract}
Over the last fifteen years, engineering has made its way into science curriculum at all levels, elementary, middle, and high school. A need to analyze students' perception the field of engineering is warranted. Previous techniques for studying representations of scientists and build on what researchers in the science field have learned from researching images of scientists. The purpose of the study was to compare two eighth grade cohorts' conceptions of engineers through the use of multiple drawings and a rubric. Half of the students were enrolled in an iSTEM Cohort and received instruction focusing on engineering while the other half of the students in this study were enrolled in a traditional cohort and received instruction via a traditional approach to science in the eighth grade. Data analysis involved two phases of eighth grade students in two cohorts, iSTEM and traditional $(\mathrm{N}=146)$. The first phase was a content analysis of the actions and artifacts of engineers at work based on the work of Capobianco, Diefes-Dux, Mena, and Weller (2011). In the second phase, illustrations were analyzed using the Draw-An-Engineer-At-Work-Test Rubric DAEWT (Thomas et al., 2016). A two-tailed, independent sample t-test was used to compare illustrations from each group. It was discovered that more themes of engineering emerged from students in the iSTEM Cohort than the traditionally taught students. Data revealed a significant difference $(\mathrm{p}<.05)$ in the portrayal of the use of science as related to the work of an engineer and the field of engineering with the iSTEM Cohort when compared with traditionally taught eighth grade students. The Draw-An-Engineer-at-Work Test when evaluated with the Draw-An-Engineer-at-Work Rubric provides researchers many visualizations of students' conceptions of how engineers use math and science in their work and can help educators understand students' conceptions concerning the engineering field.
\end{abstract}

Keywords: middle school students, STEM, perceptions, conceptions, engineering

\section{Introduction}

Over the last fifteen years, engineering has made its way into science curriculum at all levels, elementary, middle, and high school. The most obvious example is in the science standards when the National Research Council created the Next Generation Science Standards (NRC, 2012) to include engineering practices. The inclusion of engineering practices expands the previous National Science Standards (NRC, 1996) to include relevant practices germane to both science and engineering in addition to disciplinary core ideas in the science content areas and crosscutting concepts. Key ideas in science, like, asking questions are not only reinforced as guiding principles of scientific investigations but also are inclusive from the engineering perspective as in asking questions to solve problems and to elicit ideas that lead to the constraints and specifications for its solution. The primary driver of the future economy and creation of new jobs will depend on innovation, largely derived from advances in science and engineering. Science, Technology, Engineering \& Mathematics, (STEM) programs at the middle school level are becoming increasingly popular to address these engineering perspectives. It would make sense for those interested in studying how students' perceive the field of engineering to apply past techniques for studying representations of scientists and build on what researchers in the science field have learned from researching images of scientists. And so it seems appropriate that researchers shift our thinking from students' idea and illustrations about the broad science field as a whole to a narrow researchers field like engineering.

While it is generally accepted that adolescents need to begin to think and plan for career choices, researchers know that even long before children are able to express or verbalize which careers may be interesting to them they are processing information about their possible future. The goal is to expand the number of students who ultimately pursue advanced degrees to broaden the participation of more students in STEM fields. Scientific research provides little evidence about 
how to accomplish these goals. In an attempt to uncover how pre-adolescents begin constructing their earliest perceptions of science careers a popular method for assessing how children represent and identify with those in the science fields was developed. Asking children to complete the Draw-A-Scientist Test (DAST) became a commonly accepted method to capture students' ideas about scientists. The focus of this study is based on visual data students provide about careers in science and engineering.

\section{Review of Literature of Children's Illustrations of Scientists and Engineers}

Recent research has been conducted on students' perceptions of engineers (Yap, Ebert, \& Lyons, 2003; Knight \& Cunningham, 2004; Lyons \& Thompson, 2006) have used similar drawing methods, like the Draw-A-Scientist Test of decades past. The activity is called the Draw-An-Engineer Test (DAET) or Draw-An-Engineer-At-Work (DAEWT) and the purpose is to have students describe their knowledge about engineers and engineering through drawing and sometimes written responses. These illustrations are then analyzed for stereotypical features described in previous studies much like the illustrations of scientists of draw-a-scientist tests.

Much in the same way students have commonly associated beakers, chemicals, and lab coats with the tools scientists need to perform their duties, students associate engineering with fixing, building, and working on things, and when asked to draw engineers, students portrayed engineers as physical laborers, or working on cars (Oware, Capobianco, \& Diefes-Dux, 2007, Cunningham, Lachapelle, \& Lindgren-Streicher, 2005). Students often associated engineers with blueprints, computers, and safety gear and believed that engineers needed these items in order to for them to perform their work. For these reasons, the parallel between scientists and engineers is a closely linked one.

Over the past few decades in which "perceptions of scientists" research has been conducted, there have arisen a number of terms associated with it that may have contributed to confusion with respect to what this area of research is truly about (Finson \& Farland-Smith, 2013). These terms include "images," "perceptions," "visions of," "views about" or "views of," "look like," etc. Researchers argue that what is actually being examined is a concept - and for the purposes of this study will be called what researchers call conception of engineers (CoE). Svensson (1989) defined a conception as being the "... experienced meaning of one specific part of the surrounding world" (p. 531). There are likely many experiences that impact one's ideas of what an engineer is like. Those ideas build together and become a conception (i.e., a concept). The way(s) one person conceptualizes his/her experiences with different phenomena may be different than the way someone else conceptualizes the same experiences. This often depends upon which specific aspects of the phenomenon the person pays attention to most directly. How one understands any particular phenomenon will strongly influence how he/she experiences it as researchersll as influencing the approaches he/she takes to interact with it (Koballa, Bradbury, Glynn \& Deaton 2008). Karatas, Micklos, and Bodner (2011) in their study of sixth-grade students' views of the nature of engineering and images of engineers suggested that the students' concepts of engineers and engineering was fragile, unstable, and likely to change within the time frame of the interviews they conducted.

\section{Perceptions versus Conceptions}

After many years of research on students' perceptions of scientists, similar methods of analyzing pictures and gaining a perspective on how children represent their ideas about engineers, are now being evaluated for their perceptions and conceptions of engineering. Although the terms 'perception' and 'conception' are sometimes used interchangeably, these terms should be distinguished because while they are both held by individuals, a perception is an impression while a conception is an understanding. Many research studies of the past focused on perceptions, where today's contemporary studies are focusing on conceptions. Researchers use the word perceptions to describe what researcher's term an awareness based on senses and researchers use the word conceptions to describe what students have learned.

In order for us to understand these differences more clearly, it is important for us to discuss the historical relevance in terms of science education in two specific areas of research: conceptual change and students' perceptions of scientists. During the 1980's, which are considered the early years of research in students' perceptions of scientists, the emergent stereotypical image students conveyed in their drawings typically portrayed scientists as males confined to a laboratory, surrounded by dangerous chemicals while conducting dubious experiments (Barman, 1997; Chambers, 1983; Fort \& Varney, 1989; Mead \& Metraux, 1957; Schibeci \& Sorenson, 1983). Since then, researchers have collected, analyzed, and summarized research on students' perceptions of scientists, with a surface-level analysis.

At the same time, research in science education focused on conceptual change models (CCM). Much has been written about how children learn best through conceptual change models and there competing views exist with regard to how conceptions are changed (i.e., conceptual change theory) (Posner, Strike, Hewson, \& Gertzog, 1982; Dhindsa \& Anderson, 2004; Vosniadou, 2007). The various models seem to be in agreement that it has application with constructivist learning theory (CLT) since CLT highlights the substantive dimensions of prior conceptions and knowledge structures around which people organize concepts, and that active learning is necessary for changes in those conceptual organizations to occur. Much disagreement appears to focus on whether those changes take place through assimilative, accommodative, or other processes. 
Vosniadou (2007) speaks of conceptual change as one being able to "... restructure knowledge which is based on everyday experience and lay culture" (p. 48). Everyday experiences may include what one is exposed to inside and outside school, and through the media. So it is crucial to understand here that an individual can have a perception which does not necessarily mean that it is based on any kind of cognitive knowledge, it is just a perception. But, students can also hold a conception which is directly related to the knowledge they have and possibly what they have experienced. With respect to CLT and its relationship to conceptions of scientists (CoS), the goal is to help learners shift from stereotypical views toward more realistic conceptions of what scientists are like and what they do (Finson \& Farland-Smith, 2013). Those stereotypical conceptions may be personally relevant to the learner (Shope, 2006), and the educator's task becomes one of moving the learner toward a more appropriate, more coherent, and deeper conception of "scientist", or "engineer".

For the purposes of this study, researchers were interested in any differences in students' conceptions of engineers when identified with an engineering, iSTEM cohort. Therefore, the purpose of this study was to analyze and describe differences in the way eighth grade students in two cohorts, iSTEM and Traditional, represented engineers and their work in the DAEWT. This visual data set of three pictures was then analyzed through the application of the Draw-An-Engineer-at-Work Test Rubric (Thomas, Colston, Ley, Ivey, Utley, DeVore-Wedding, \& Hawley, 2016). The combination of the DAEWT directions and the DAEWT Rubric brings refinement as it enables clarities to emerge and subsequently increased detail to what one could ascertain from students about their expressed images of engineers and the engineering field. Insights into how engineers use math and science in their work will be explored along with the idea that engineers are their own subset under the broader umbrella of scientists. Through the examination and evaluation of middle school students' pictures researchers, as researchers, gain a wealth of information while looking broadly at one's perceptions or conceptions over multiple pictures. In the same way as the development and application of a single instrument and protocol has provided for countless research studies about scientists, researchers anticipate probing debates and lively discussion amongst researchers across fields of engineering. Mathematics and computational tools are critical to both science and engineering, though these elements have yet to be studied in pictures and specifically with these targeted populations.

\subsection{Modifications to DAST and DAET}

In 2003, Farland modified the DAST directions from a simple "draw a scientist" to "Imagine that tomorrow you are going on a trip (anywhere) to visit a scientist in a place where the scientist is working right now. Draw the scientist busy with the work this scientist does. Add a caption, which tells what this scientist might be saying to you about the work you are watching the scientist do. Do not draw yourself or your teacher".

Farland (2006) then used the information collected from these specific directions to create a rubric based on the variations collected, observed, and analyzed to create a comprehensive picture of students' perceptions of scientists. Using a rubric to analyze children's illustrations of scientists is a contemporary approach and appropriate because it allows for individual creativity as there is no right or wrong ansresearchersr for illustrations as there often is with science content. In a study to be published in 2016, Thomas et al. applied a similar approach to the Draw-An-Engineering-at-Work Test, thus creating the first ever rubric to analyze illustrations of engineers. Through the examination and evaluation of students' pictures with specific directions a wealth of information was attained while looking broadly at one's conceptions over multiple pictures. The next section will discuss the purpose of using three images to understand students' visual data of scientists and engineers.

\subsection{Multiple Representations of Scientists \& Engineers}

For decades, researchers had been convinced that one stereotypic image of scientists existed among children worldwide (Chambers, 1983; Chiang \& Guo, 1996; Fung, 2002; Maoldomhnaigh \& Hunt, 1988; Newton \& Newton, 1992; 1998; Song, Pak, \& Jang; 1992; She, 1998). This stereotypic image includes, a white male in a laboratory setting with beakers and/or chemicals. While most people find this amusing and even can recall meeting or seeing a scientist in media or real life to reinforce the typical stereotype about scientists, is does not serve educators well for encouraging students to enter the field of science.

More recently, one conclusion to be drawn from all these is that children have a tendency to view engineers in stereotypical ways (mechanics or laborers fixing things) much in the same way they view scientists in stereotypical ways (chemists in laboratories surrounded by bubbling liquids). Hence, what researchers glean from these studies is that the initial conceptions of engineers and scientists held by children are somewhat limited and are in want of expansion.

The purpose of having students create multiple drawings of scientists and engineers is an attempt to expose and possibly exhaust the conceptions students' hold about people who work in these fields. It is reasonable to assume that in multiple pictures students would have a sufficient opportunity to represent their ideas about anything, in this case scientists and engineers. For example, if they hold a view of the work of science and the true nature of who can be a scientist, it will be evident across the three pictures. On the other hand, if a student draws the same image consecutively there is good reason 
to believe it is the student's only view (Farland-Smith \& McComas, 2007).

This idea that young children hold a range of perceptions versus the commonly accepted singular, insular image was something gained from evaluation with a rubric. It is during this process that competing and/or conflicting images can be uncovered. For this reason, the multiple drawing task to gain a wider view of what students really know about scientists rather than limiting students to one opportunity to represent their view. Most of us, if asked to draw only one image of a scientist (or anything else for that matter), are likely to draw a stereotypical image to get the point across even though researchers may appreciate the limitations of that single drawing. With multiple opportunities, if a student draws scientists of differing ethnicities, of both genders doing work in a variety of settings it is reasonable to assume that they have a sufficiently broad view of the work of science and engineering. Furthermore, combining a contemporary perspective and creative method of analyzing student perceptions may be helpful in developing a theoretical understanding of how students interpret scientists, engineers, and their work. It also provides a language for researchers to use in discussing these illustrations and frames the context (i.e., appearance, location, activity), for the visual representations of scientists to ease comparison.

For example, data from a preliminary study evaluating the use of multiple pictures showed that if researchers were to make assumptions about what students think of scientists with respect to activity from a single drawing, researchers would be correct only $24 \%$ of the time. In $76 \%$ of cases, the students' first drawing is not their only conception of a scientist. The following pictures demonstrate the range of perceptions students may hold about scientists and is included for evidence that the first picture a child draws may not contain all their feelings and/or conceptions of scientists (Farland-Smith \& McComas, 2007). What follows is a discussion of how using rubrics and multiple pictures moves beyond evaluation to an actual understanding of students' visual representations of scientists. A discussion of how value is assigned when scoring three pictures of scientists will be described in the next section.

\section{Design}

The purpose of our study was to compare iSTEM and Traditional eighth grade students' conceptions of engineers through the use of multiple drawings and a rubric. Data collection took place at the end of the first year for students enrolled in the iSTEM Cohort, and at the end of the year of eighth grade Traditional science course. In each group, the teachers followed the script for test administration. The teacher then handed out a folded piece of paper for the DAEWT. Each student was given a number for coding at the top of the paper and indicated their gender in a space provided. The specific prompt was,

"Draw an engineer at work." In this space you will create an illustration of an engineer. There are no wrong ansresearchersrs-so think about what you know about engineers' work and draw the ideas and details you remember. This is not a test of your artistic skills-so do not worry about your drawing ability. You will notice that there are a few more opportunities for you to describe your engineer (and explain in drawing too). So, now, let's begin. Please draw an engineer-at-work in the box provided. Lay down your pencil once you are satisfied with your drawing and wait for my next direction."

After the student completed the first picture, each student was asked to answer the questions below each drawing space. The questions were as follows: 1) How is this engineer using math? 2) How is this engineer using science? 3) Is this engineer a male or a female? 4) Write a sentence about the engineer's work.

When the teacher noticed most of the students were finished with the first picture students were then instructed to draw two more pictures of engineers using the same prompt. In total, 215 students created three pictures of engineers in both groups. Teachers monitored the class to ensure students did their own work and the teachers did not provide any additional information if a student asked for more information.

\subsection{Participants}

A public school district in the Midwestern United States was selected for this study based on the fact that they offered an iSTEM cohort for eighth grade students. The iSTEM program can be described as an interest-based program for both boys and girls in eighth grade. In order to be accepted into the program all students require to complete a three question survey about their interests. Once the applications were reviewed no one is excluded. The curriculum of iSTEM cohort compared with the Traditional cohort was centered on the pedagogy of the team of teachers which focused on the applications of practical engineering in every content area, not only science. The Traditional students learned science from a traditional textbook, where the iSTEM students experienced science through problem based scenarios involving engineering that were designed by their team of teachers.

Two-hundred and fifteen sets of three drawings were collected from the two comparison groups. The breakdown of each was as follows; initially 104 drawings were collected from the Traditional sample; and 111 drawings were collected from the iSTEM Cohort. Thirty-one of the DAEWT's (sets of three pictures) were removed from the Traditional sample because they were incomplete. The Traditional sample consists of 41 females and 32 males. In iSTEM Cohort, 39 sets of 
three pictures were removed randomly out of 111 as a means of equalizing the groups. It consists of 33 females and 40 males. No attempt was made to compare the two groups based on socioeconomic data. No surveys were collected from public school teachers on the differences in curriculum. Therefore, no speculation on the type of science curriculum can be made except to generalize the differences between the iSTEM cohort which can be described as the deliberate focus of the teachers to develop their curriculum as a team with explicit focus on problem-based learning about real-life engineering scenarios and the Traditional cohort which received their instruction strictly from the textbook. It's important to acknowledge that a stronger initial interest in the iSTEM students could have attracted students and accounted for the differences versus instruction. So it is not really known which variable.

\subsection{Research Questions}

In the first phase, a content analysis of the actions and artifacts of engineers at work was performed based on the work of Capobianco et al. (2011). The primary question researchers focused on was: 1) Are there differences in the actions and artifacts of engineers between the iSTEM cohort and the Traditional eighth grade cohort?

In the second phase, illustrations researchers analyzed using the DAEWT (Thomas, et al., 2016). The focus of this phase researchers on the following questions: 2) Is there a difference in the perception of how engineers use math be researchers the iSTEM cohort and the Traditional cohort of eighth grade students? 3) Is there a difference in the perception of how engineers use science between the iSTEM cohort and the Traditional cohort of eighth grade cohort? 4) What are the differences in the perception of gender of engineer's between the iSTEM cohort and the Traditional eighth grade cohort? 5 ) Is there a difference in the perception of the work of engineers between the iSTEM Cohort and the Traditional cohort?

\subsection{Procedures}

Students in eighth grade in a large public school district were asked to complete the DAEWT. Half of the de-identified students were in a Traditional eighth grade cohort while the other half of the de-identified students were in an iSTEM cohort. The drawing assignment was part of their normal curriculum by their teachers, all were willing participants. The researchers both scored the illustrations using Thomas et al. (2016) DAEWT Rubric and performed independent t-tests in each category to analyze differences in perceptions. Inter-rater reliability was eighty percent which was established once both coders were trained and by each coder scoring the drawings and comparing their scores.

The first phase was a content analysis of the actions and artifacts of engineers at work. All actions (fixing) and artifacts (cars) included in illustrations were tallied and categorized for each sample group in the same way Capobianco et al. (2011) coded illustrations of engineers. The action of the engineer was labeled and a category was created based on the information provided by the student in the illustration. The artifacts were described as the part of the illustration receiving the action, i.e. a car, a building, etc.

In the second phase, illustrations were analyzed using the Draw-An-Engineer-At-Work-Test Rubric DAEWT (Thomas et al., 2016). The Draw-An-Engineer-At-Work Test (DAEWT) Rubric allowed the researchers to assign a numerical score in four separate and specific categories: 1 ) the use of math in engineering $(0-2) ; 2)$ the use of science in engineering $(0-2) ; 3)$ gender stereotypes (0-3); and 4) the work of an engineer (0-3). The DAEWT Rubric assigns a score from 0 to 2 for math and science categories and assigns a score from 0 to 3 for gender and work of an engineer categories within each picture. Details of the scoring of the Use of Mathematics and the Use of Science are located in the Appendix A.

\section{Results}

\subsection{Phase 1. Content Analysis of the Actions and Artifacts of Engineers at Work}

From the inductive analysis, researchers identified two central domains that reflected students' perceptions on the DAEWT. These domains were in response to the question stated below the drawing, "What is the engineer doing?" responses were identified, and coded, based on Capobianco et al. (2011) in which the terms actions and artifacts were used. In an effort to separate actions from artifacts responses were recorded in each of these two central domains which including the following: (1) actions performed by an engineer (e.g., building) and (2) artifacts used by an engineer (e.g., engine), as identified by Capobianco et al. (2011). Patterns that emerged based on the content analysis are reported in Table 1 below and will be now discussed. More artifacts were included (43) than actions by engineers for the total sample $(\mathrm{N}=146)$.

Table 1.1. Comparison of Actions vs Artifacts

\begin{tabular}{lll}
\hline & Frequency & Percent \\
\hline Actions & 8 & 15.7 \\
Artifacts & 43 & 84.3 \\
Total & & 100.0 \\
\hline
\end{tabular}


Recall that in the first phase, our primary question focused on the differences in the actions and artifacts of engineers between the iSTEM cohort and the traditional cohort. So upon closer examination, Table 1.2 reveals that the iSTEM students $(100 \%)$ provided evidence of all categories in actions domain (8), while the traditional cohort only provided evidence for six of the eight categories in this domain (75\%) in their drawings. With respect to artifacts, the iSTEM cohort also portrayed more categories ( 37 out of $43,86.05 \%$ ) than their Traditional peers ( 32 out of $43,74.42 \%$ ), as summarized in the table below. The frequency of actions and artifacts are displayed in Figure 1 which reveals that the iSTEM cohort had more frequent categories emerge (90 drawings in actions domain and 302 drawings in artifacts domain) than their Traditional peers (68 drawings in actions domain and 232 drawings in artifacts domain) as shown in Figure 1. It is important to clarify here that the total frequency may not be equal to the total number of students' drawings because some students portrayed more than one category in one image, and other students did not portray any category.

Table 1.2. Comparison between Groups

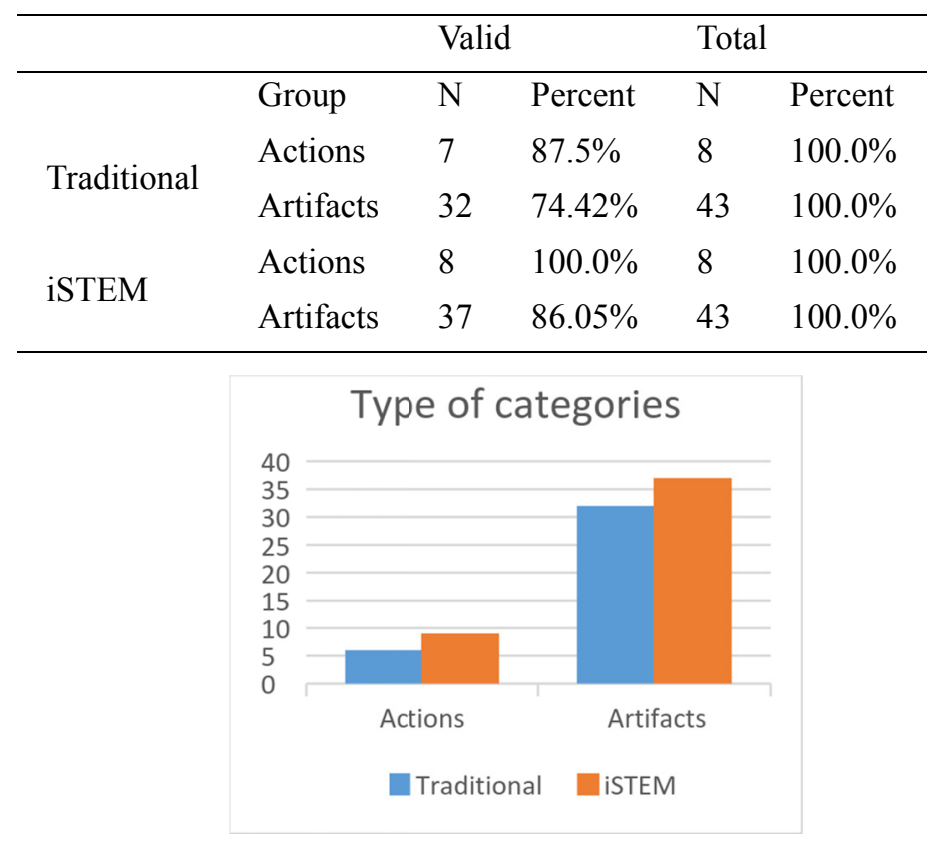

Figure1. Comparison between Groups

\subsection{Phase 2. The Draw-An-Engineer at Work Rubric}

The data (drawings) were collected, and each picture was scored using the DAEWT Rubric (Thomas et al., 2016). The DAEWT Rubric was developed specifically to score the modified DAEWT (Thomas et al., 2016) and assigns a numerical score in four separate in four specific categories: 1) the use of math in engineering; 2) the use of science in engineering; 3 ) gender stereotypes; and 4) the work of an engineer in general. Recall that the DAEWT Rubric assigns a score from 0 to 2 for math and science categories and assigns a score from 0 to 3 for gender and work of an engineer categories within each picture. A copy of the DAEWT Rubric appears in Appendix A. At the analysis of scoring, each of the three drawings was assigned a score and either labeled No Conception (0), Basic Conception (1), or Advanced Conception (2) for the math and science categories.

\subsection{Math, Science, Gender, \& Work of an Engineer}

The first question researchers interested in was the difference of how the iSTEM Cohort and the Traditional cohort perceive the use of math by engineers, and researchers were looking for a statistical significance between the two groups. Recall each picture in a set of three per student had the ability to be scored 0-2. Therefore, the highest possible score would be 6 on any given set of three pictures researchers term the DAEWT. Each student had a sum score in this category. The sum of each student was then compared between groups. Table 2 shows that the mean scores for both groups with respect to the math, science, gender, and work of engineers categories. The iSTEM Cohort had the higher mean scores when compared with the Traditional sample in every category. See Table.2 Comparison of Means between iSTEM and Traditional samples. The mean scores were then compared with each other with an independent sample $t$-test. The mean scores did not differ significantly with respect to the math and gender categories (the $p$ value were 0.1 and 0.1 respectively), but differed significantly with respect to science and work of engineers categories (the $p$ value was less than 0.001 ), at the .05 level of significance. 
Table 2. Comparison of Means between iSTEM and Traditional Cohorts

\begin{tabular}{llllllll}
\hline Group & Traditional & \multicolumn{7}{c}{ iSTEM } \\
\hline & $\mathrm{N}$ & Mean & Std. & $\mathrm{N}$ & Mean & $\begin{array}{l}\text { Std. } \\
\text { Deviation }\end{array}$ & $\begin{array}{l}\text { Sig. } \\
(2 \text {-tailed })\end{array}$ \\
Math & 73 & 2.61 & 1.41 & 73 & 3.01 & 1.51 & .103 \\
Science & 73 & 1.54 & 1.46 & 73 & 2.69 & 1.24 & .000 \\
Gender & 73 & 4.19 & 1.52 & 73 & 4.53 & 1.62 & .191 \\
Engineering & 73 & 3.24 & 1.53 & 73 & 4.56 & 1.83 & .000 \\
\hline
\end{tabular}

\section{Discussion}

\subsection{Phase One}

Results indicated that the students in the iSTEM Cohort drew broader actions of engineers and also a greater number of actions for engineers. The eight different actions that emerged in this study were: 1) fixing, 2) problem solving, 3) scientific process, 4) programming, 5) measuring, 6) presenting ideas, 7) building, and 8) professor. Capobianco et al. (2011) reported the actions of the engineers in children's pictures as fixing, building, making, working, and designing. Fixing and building are consistent with their findings of Capobianco et al. (2011). Researchers agree with their results as researchers too, found that students associate engineering with fixing, building, and working on things, and when asked to draw engineers, students portrayed engineers as physical laborers, or working on cars (Oware, Capobianco, \& Diefes-Dux, 2007, Cunningham, Lachapelle, \& Lindgren-Streicher, 2005). However, researchers would add that students also associate presenting ideas, being a professor, problem solving, programming and scientific process with engineering in this study as well. Researchers believe that because they asked students to draw three pictures of engineers, not one as in past studies that they were able include more ideas about the actions of engineers simply because they had three times the opportunities in which to do so. Recall the purpose, as mentioned earlier of having students create multiple drawings of scientists and engineers, is an attempt to expose and possibly exhaust the conceptions students' hold about people who work in these fields. This study appears to have exhausted new conceptions in terms of the engineering field with the iSTEM students.

\subsection{Phase Two}

There were no significant difference between the two groups, iSTEM \& Traditional cohorts, in terms of the use of how engineers use mathematics and the gender of engineers. Why was there no difference in how students from both groups perceived how engineers used math in engineering? Could it be that kids see math as math, a tool? They are aware that math is involved as measuring emerged in both groups as an action. For gender, recall the categories, no conception, traditional, nontraditional and expanded. Since there was no significant difference between the two groups, the majority of the student pictures scored fell into the traditional category and according the Thomas et al.'s Rubric (2016) it means single individual depicted as a male.

There was a significant difference speculation/ limitation between the groups, iSTEM and Traditional, in terms of how engineers use science and the work of engineering. It is easy to explain the difference in the perception of the work of engineers because the team of teachers in the iSTEM Cohort focused on teaching about engineering where the group in Traditional science classes focused on science. The iSTEM teachers reported intentional and deliberate instructional methods, so it is no surprise that those students exhibited a significant difference in their conception of the work of engineers. For example, the teachers brought in engineers from the local community to talk with the iSTEM cohort and discuss their education and preparation for the jobs they now do. It speaks to their classroom instruction and the work the teachers were doing on the iSTEM cohort. Learning eighth grade science in a cohort that is identified as iSTEM did appear to makes a difference in their conceptions and the understanding of the work of engineers. This grouping also makes a difference in terms of the use of science by engineers. It appears that these two conceptions/or perceptions are related. Why mathematics and gender were impacted by the grouping of students who focused on engineering is interesting as one might predict the science and mathematics of engineering go hand and hand. However, it appears to these students that is not the case, science and engineering appear to be impacted to a greater magnitude. 


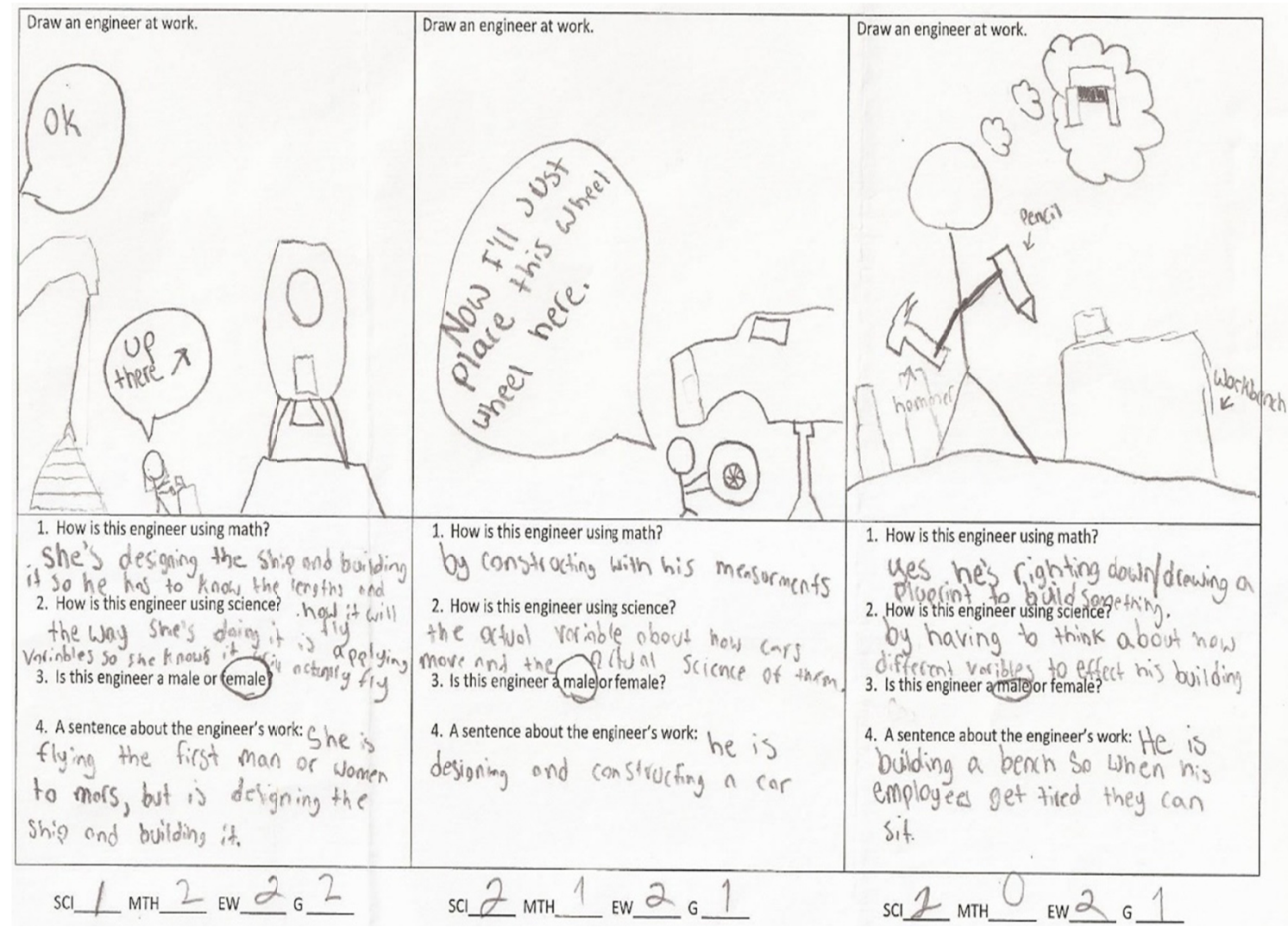

Figure 2. iSTEM Example

The picture above, Figure 2, is an example from a male in the iSTEM cohort. It was selected to illustrate the differences portrayed in this study when compared to Figure 3 a Traditional students' DAEWT. In terms of math use by engineers, this particular student had a variety of scores, $2,1,0$. In the first picture, a female is designing and building a space ship and indicates the engineer has to know the length and how it will fly. This picture was scored a 2 because it reflects both the what and why of the use of mathematics. For example, the student discussed needing to know the length and why that was important to flight. In the second picture, a male engineer is "constructing with his measurements". This picture was scored a 1 because it reflects a what but not a why of the use of mathematics. For example, the student identifies measurements, but not why the engineer might use measurements. In the third picture, a male engineer is writing down and drawing a blueprint to build something. This picture was scored a 0 because no elements of mathematics were included. Overall this student has an inconsistencies in his ideas of the use of mathematics in engineers work.

In terms of science use by engineers, this particular student had a variety of scores, 1, 2, 2. In the first picture, a female is applying variables to the space ship so she knows it will actually fly. This picture is scored a 1 because she understands that variables are an element of science investigation, this is the what. However, the what, the variable, however it is not clear, nothing to do with the why, flying. In the second picture, it is scored a 2 because a male engineer because it discusses how cars move and the actual science of them. In this picture it connects with the illustration to assume the child meant how to make the wheel move. In the third picture, it is scored a 2 because a male engineer is thinking about how different variables will affect his building. This explanation connects with the drawing because it shows a workbench and pencil and includes a thinking bubble, implying that engineers think about variables as they build or before they build. This is different from the first picture, which mentions the use of variables, but it is not connected to the picture. The third picture includes a cause and effect relationship where the first picture does not.

In terms of gender the picture was scored 2, 1, 1 . This is because a female was portrayed in the first picture and two males were portrayed in the second and third pictures.

All students were asked as part of DAEWT to include a sentence about the engineer's work. All three drawings scored $2 \mathrm{~s}$ as it appears to be some consistencies about the work engineers do. In the first picture, the engineer is designing a space ship and building it in order to be the first to travel to Mars. In the second picture, the engineer is designing and constructing a car. In the third picture, the engineer is building a bench for his employees. All of these pictures included aspects discussed in the DAEWT Rubric which are labeled basic conception which suggest engineers create plan or design new things but does not reference a specific problem or need. Note two assumed problems, first trip to mars and nowhere for his workers to sit, but not specifically stated. 


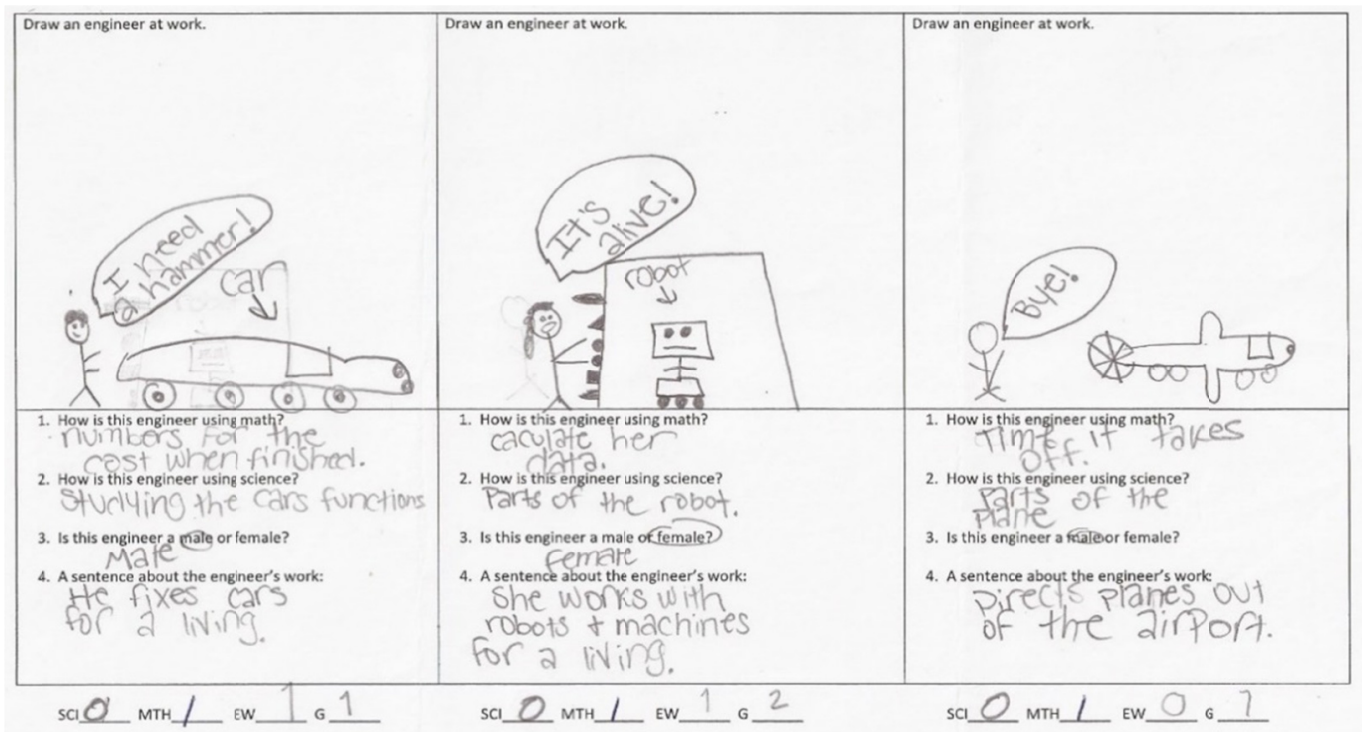

Figure 3. Traditional Example

The picture above, Figure 3, is an example from a female in the Traditional cohort. It was selected to illustrate the differences portrayed in this study when compared to Figure 2, an iSTEM students' DAEWT. In terms of math use by engineers, this particular student had consistent scores across all three pictures, $1,1,1$. In the first picture, the student drew a male includes the idea that numbers are involved in the cost of the cars but not the function. This picture was scored a 1 because numbers are not a mathematical concept but it relates to the cost. In the second picture, a female engineer is calculating her data. This picture was scored a 1 because it reflects what she is doing but not why. In the third picture, a male engineer is referencing time in terms of the plane taking off. This picture was scored a 1 because time is an element of math but not the specific to the time needed for takeoff, i.e. every fifteen minutes. Overall this student was consistent in her ideas of the use of mathematics in engineers work.

In terms of science use by engineers, this particular student also had consistent scores, $0,0,0$. In the first picture, a male engineer is studying the cars functions. This picture is scored a 0 because according to the rubric the science is vague or nonsensical. In the second picture, it is scored a 0 because a female engineer is doing "parts of the robot", again vague or nonsensical. In the third picture, it also scored a 0 because it is not a complete thought or sentence, "parts of the plane". Overall no scientific conceptions related across illustrations. Overall this student was also consistent in her ideas of the use of science in engineers work.

In terms of gender the picture was scored 1,2,1. This is because a female was portrayed in the second picture and two males were portrayed in the first and third pictures.

All students were asked as part of DAEWT to include a sentence about the engineer's work. The three drawings were scored $1,1,0$. In the first picture, the engineer is fixing cars for a living. In the second picture, the engineer is working with robots and machines for a living. In the third picture, the engineer is directing planes out of the airport. All of these pictures included aspects discussed in the DAEWT Rubric which are labeled naive conception and no conception. Naïve conception suggests engineers are doers or fixers.

These two pictures were selected because researchers believe they represent the overall statistical differences between the iSTEM and Traditional cohorts. For example, both males and females were drawn by both groups, suggesting no significant difference between the groups. In terms of math, both groups hold basic conceptions of math. However, in terms of science, it is clear from the use of the words variable and experimental design that the iSTEM students portrayed more knowledge about experimentation in general. In terms of engineers, the difference is between the designers and doers. Researchers also do not know exactly what kinds of in class experiences these students were exposed to, for example, in classrooms researchers tend to demonstrate that engineering does have something to do with building, as there are many activities which require students to build in classrooms.

\section{Conclusion}

The Draw-An-Engineer-at-Work Test when evaluated with the Draw-An-Engineer-at-Work Rubric provides researchers many visualizations of students' conceptions concerning the engineering field. The DAEWT is also unique because it evaluates each students' set of illustrations (3) of engineers at work in the following categories: 1) the use of math in engineering; 2) the use of science in engineering; 3 ) gender stereotypes; and 4) the work of an engineer in general. After analyzing 438 illustrations between the two cohorts that approached eighth grade differently it appears that there are 
significant differences in the conceptions between groups. Data revealed a significant difference in the conceptions of the use of science and engineer at work with the iSTEM Cohort when compared with traditionally taught eighth grade students. Comparison of gender of engineer's between the two cohorts did not reveal any significant difference, as did the use of mathematics in engineering. It should also be noted that students in the iSTEM Cohort had a broader conception of the work engineers both in terms of the quantity and quality of the advanced conceptions of engineers.

\section{References}

Capobianco, B. M., Diefes-Dux, H. A., Mena, I., \& Weller, J. (2011). What is an engineer? Implications of elementary school student conceptions for engineering education. Journal of Engineering Education, 100(2), 304-328. http://dx.doi.org/10.1002/j.2168-9830.2011.tb00015.x

Chambers, D. (1983). Stereotypic images of the scientist: The draw-a-scientist test. Science Education, 67(2), 255-265. http://dx.doi.org/10.1002/sce.3730670213

Chiang, C., \& Guo, C. (1996). A study of the images of the scientist for elementary school children. Paper presented at the National Association for Research in Science Teaching, St. Louis Missouri.

Cunningham, C., Lachapelle, C., \& Lindgren-Streicher, A. (2005). Assessing elementary school students' conceptions of engineering and technology. Paper presented at the annual American Society for Engineering Education Conference $\&$ Exposition, Portland, OR.

Dhindsa, H. S., \& Anderson, O. R. (2004). Using a conceptual-change approach to help presevice science teachers reorganize their knowledge structures for constructivist teaching. Journal of Science Teacher Education, 15(1), 63-85. http://dx.doi.org/10.1023/B:JSTE.0000031463.56206.a5

Farland, D. (2006). Effect of historical, non-fiction, trade books on elementary students' perceptions of scientists. Journal of Elementary Science Education, 18(2), 33-50. http://dx.doi.org/10.1007/BF03174686

Farland-Smith, D., \& McComas, W. F. (2009). Teaching the human dimension of science. Science and Children, 46(9), $32-35$.

Finson, K., \& Farland-Smith, D. (2013). Applying Vosniadou's conceptual change model to visualizations on conceptions of scientists. In Visual Data and Their Use in Science Education, Eds.by Kevin Finson and Jon Pederson. Information Age Publishing Inc., 47-76.

Fung, Y. (2002). A comparative study of primary and secondary school students' images of scientists. Research in Science \& Technological Education, 20(2), 199-213. http://dx.doi.org/10.1080/0263514022000030453

Karatas, F., Micklos, A., \& Bodner, G. (2011). Sixth-grade students' views of the nature of engineering and images of engineers. Journal of Science Education \& Technology. http://dx.doi.org/10.1007/s10956-010-9239-2

Knight, M., \& Cunningham, C. (2004). Draw an engineer test (DAET): Development of a tool to investigate students' ideas about engineers and engineering. Paper presented as the annual American Society for Engineering Education Conference \& Exposition, Salt Lake City, UT.

Lyons, J., \& Thompson, S. (2006). Investigating the long-term impact of an engineering-base GK-12 program on students' perceptions of engineering. Paper presented at the annual American Society for Engineering Education Conference and Exposition, Chicago, IL.

Maoldomhnaigh, M., \& Hunt, A. (1988). Some factors affecting the image of the scientist drawn by older primary school pupils. Research in Science \& Technological Education, 6, 159-166. http://dx.doi.org/10.1080/0263514880060206

Mead, M., \& Metraux, R. (1957). Image of the scientist among high school students. Science, 126, 384-390. http://dx.doi.org/10.1126/science.126.3270.384

National Research Council (NRC). (1996). National science education standards. Washington, D.C.: National Academy Press.

National Research Council (NRC). (2012). A Framework for K-12 science education. Practices, Crosscutting Concepts, and core ideas. Washington, D.C.: National Academy Press.

National Research Council (NRC). (2012). A Framework for K-12 science education. Practices, Crosscutting Concepts, and core ideas. Washington, D.C.: National Academy Press.

Newton, D., \& Newton, D. (1998). Primary children's perceptions of science and the scientist: Is the impact of a national curriculum breaking down the stereotype? International Journal of Science Education, 20, 1137-1149. http://dx.doi.org/10.1080/0950069980200909

Newton, D., \& Newton, L. (1992). Young children's perceptions of science and the scientist. International Journal of 
Science Education, 14(3), 331-348. http://dx.doi.org/10.1080/0950069920140309

Oware, E., Capobianco, B., \& Diefes-Dux, H. (2007). Gifted students' perceptions of engineers? A study of students in a summer outreach program. Paper presented as the annual American Society for Engineering Education Conference \& Exposition, Honolulu, HI.

Posner, G. J., Strike, K. A., Hewson, P. W., \& Gerzog, W. A. (1982). Accommodation of a scientific conception: Towards a theory of conceptual change. Science Education, 66(2), 211-227. http://dx.doi.org/10.1002/sce.3730660207

She, H. (1998). Gender and grade level differences in Taiwan students' stereotypes of science and scientists. Research in Science \& Technological Education, 16(2), 125-135. http://dx.doi.org/10.1080/0263514980160203

Shope, R. E. III. (2006). The Ed3U science model: Teaching science for conceptual change. Retrieved at http://theaste.org/publications/proceedings/2006proceedings/shope.html

Song, J., Pak, S., \& Jang, K. (1992). Attitudes of boys and girls in elementary and secondary schools towards science lessons and scientists. Journal of the Koran Association for Research in Science Education, 12, 109-118.

Thomas, J., Colston, N., Ley, T., Ivey, T., Utley, J., DeVore-Wedding, B., \& Hawley, L. (June, 2016, Under Review). Developing a rubric to assess drawings of engineers at work. Paper presented at the Annual Conference and Exposition of the American Society for Engineering Educators, New Orleans, LA.

Vosniadou, S. (2007). Conceptual change and education. Human Development, 50, 47-54. http://dx.doi.org/10.1159/000097684

Yap, C., Ebert, C., \& Lyons, J. (2003). Assessing students'perceptions of the engineering profession. Paper presented as the South Carolina educators for the practical use of research annual conference, Columbia SC.

\section{(cc) $\mathrm{Br}$}

This work is licensed under a Creative Commons Attribution 3.0 License. 